\title{
Innovation Practices and Firm Performances: An Empirical Investigation in Turkey
}

\author{
Fahri Apaydın \\ Faculty of Economics and Administrative Sciences, Yalova University \\ İktisadi ve İdari Bilimler Fakültesi, Yalova Üniversitesi \\ Safranyolu, Yalova, Turkey \\ Tel: +90-216-814-9932Ｅ-mail: apaydin@yalova.edu.tr
}

Received: July 9, $2011 \quad$ Accepted: July 22, $2011 \quad$ doi:10.5430/jms.v2n3p35

\begin{abstract}
In this empirical research, how marketing managers evaluate their firms' performances and use this evaluation to decide to make innovation in Turkey is examined. They use some standards which are past performance of the firm, target performance of the firm, competitor performance, and average performance of the industry to compare and evaluate the firms' performances. It is hypothesized that marketing managers and owners of the firm compare the firms' current performance with these four standards at the same time to decide when to make innovation relating to any aspects of the firm, either management style or products. Relationship between the comparison of the firm's performance with these standards and innovation are searched in the same regression model. The results reveal that apart from other antecedents of making innovation, managers' evaluation of performance results play a significant role in making innovation.
\end{abstract}

Keywords: Innovation, Performance evaluation

\section{Introduction}

Performance of firms has been a significant part of empirical research in the management field. Measuring the performance of firms is an important component of strategic marketing management (Chakravarty, 1986; Zou and Cavusgil, 2002). Performance measurement systems have an activity of scanning environment and fundamental role in providing marketing managers with necessary information. These systems inform marketing managers about the success of marketing activities of the firms. When marketing managers are not satisfied with the results, they can make decisions to make necessary changes in marketing strategies and activities (Epstein and Roy, 2005). Thus, firms spend great efforts to generate performance standards to obtain better information to measure and manage firm performance.

Performance measurement systems have to include leading indicators that give insight into the firms' competitive position and serve as predictors of future performance. In fact, performance measurement and performance evaluation processes are paying attention to both internal and external environment (Pelham and Lieh, 2004). Marketing managers use the measurement systems to follow the changes in the external environment not to stay behind the competition. Not to stay behind the competition, firms make innovation when they feel that they are not performing well. The question they try to answer is when to make innovation, and that they perform worse than the performance standards they compare the performance of their firms with might serve as an indicator of the time to make innovation. These standards are past performance of the firm, target performance of the firm, performance of the competitors, and the average performance of the industry they are operating in. This comparison helps them to identify their position within the market and the need to make innovation.

\section{Performance Evaluation}

In the marketing literature, performance measurement and performance evaluation are confused with each other and used interchangeably. Nonetheless, they are completely distinct concepts in that performance measurement is an activity of describing performance results with figures, while performance evaluation is the activity of comparing performance results with some standards chosen by managers and judging and interpreting these results (Tekin, 1993; Smith and Bolton, 2002; Wirtz and Mattila, 2001). Performance evaluation requires comparison of the performance results, obtained after measurement, with some standards, and managers develop some ideas and feelings during the evaluation process. These ideas and feelings determine the level of manager satisfaction about the performance. Two different marketing managers might perceive the same performance result in completely different ways due to some factors such 
as psychology, perception, knowledge level, tenure, etc. Based on their satisfaction level, they decide whether to make innovation or not.

Performance measurement is done in various methods and ways as an ongoing activity in firms and marketing managers and owners of the firms consider the results as an indicator of the success level of their decisions and activities (Kennerley and Neely, 2003; Bourgeois, 1980; Coşkun, 2006; Geringer and Hebert, 1991). In the literature, performance measurement is scrutinized in a great number of studies. In these studies, researchers have used various performance standards as comparison standard. Main comparison standards used in such studies are past performance of the firm (Johnston and Kim, 1994; Greve, 1998), target performance of the related term (Kernan and Lord, 1991; Johnston and Kim, 1994), performance of the main competitor/s (Pelham and Lieh, 2004; Matsuno and John, 2000), and/or average performance of the industry (Brooks and Coleman, 2003; Greve, 1998; Piercy et. al., 1998; Hansen and Wernerfelt, 1989; Dess and Robinson, 1984). However, none of these standards have been used in the same model or research, so this paper could be the first examining them in the same model.

It is posited that marketing managers should use these four standards at the same time to consider the firm's success. Just using one of them might mislead the marketing managers in that if the marketing is expanding, and the increase in the sales is behind the expansion of the market but higher than the past performance, marketing managers might feel that they are on the right track though they might not be as their competitors could be performing better.

\section{Innovation}

The term innovation largely refers to any breakthroughs related to products, production facilities, and/or organization of the firms in the marketing and management literature (Han et. al., 1989; Arndt and Bigelow, 2000). The environment that firms are operating in is not constant, and there is a rapid change which is a result of political, economic, behavioral, sociological, and technological sources in it. This change affects the firm both directly and indirectly. A firm, like a living organism, needs to adapt to the changing environment to sustain its existence. Marketing function regulates the flow of resources across the firm, so its main function is to observe the environment and anticipate when innovation is needed (Cooper, 2000; Siva as and Dwyer, 2000). Deciding to make innovation mainly depends on marketing managers' willingness. If they see that the firm is not performing satisfactorily, they may consider making innovation regarding any aspects of the firm, e.g. management styles, production systems, or products. Especially, when companies perform worse than the standards mentioned above, they are apt to make innovation, which indicates that the firm fails to follow the change in the environment.

In the literature, some antecedents to make innovation are mentioned. Some of these antecedents are having an organizational culture which supports innovation, having capacity to make innovation, and having organizational structure which enables innovation (Hurley et. al., 2000). Innovation impacts the firm's competitive advantage to a great extent. Marketing managers' evaluation of the competitors facilitates innovation as they feel obliged to make innovation not to lose competitive advantage when they recognize that their competitors perform better than their firms. The process of decision making relies on environmental scanning, interpretation, and learning. Managers observe the environment by scanning the actions of the actors such as customers, competitors, regulators, and suppliers in the environment. Organizations tend to commit to activities that they have done well in the past. After comparing their performance with competitors' performance and the average performance of the industry, if they are better than them they may think that they are doing things well and abstain from making innovation. Making innovation is a kind of risk taking, so high performance causes managers to be less likely to make change. Innovation has some short term and long term effects which are difficult to evaluate, and that is why it is considered as risk bearing. Thus marketing mangers' interpretations of performance results may interfere in the change process (Greve and Taylor, 2000).

Lindsley et al. (1995) explore the possibility of efficacy-performance spirals in individuals, groups, and organizations. With spiral, they mean the cyclical relationship between efficacy and performance, and they posit that this relationship exists. Likewise, it is suggested in this paper that there is a cyclical relationship between performance and innovation. Firms make innovation to improve performance, and in return after evaluating the performance results, they make decisions whether it is needed to make further innovation and about which aspects of the firm to make innovation. In this paper, the relationship between the comparison of the performance of the firm with performance standards used by marketing managers mentioned above and managers' decisions about making innovation in the near future are examined in a regression model (Figure). Based on the literature review, the hypotheses are:

H1: If the firms perform better than the past performance, they don't make innovation.

H2: If the firms perform better than the target performance of the firm, they don't make innovation.

H3: If the firms perform better than the competitors' performance, they don't make innovation. 
H4: If the firms perform better than the average performance of the industry, they don't make innovation.

\section{Methodology and Results}

\subsection{Sample}

A random sample of small and medium sized firms which are members of İstanbul Chamber of Commerce was drawn. Small and medium sized firms are chosen because most of the firms in Turkey are put into this category and they play a significant role in the industry. To be able to make generalization, firms were chosen from a variety of industries including finance, retailing, wholesaling, manufacturing, etc. This is relevant because the researched subject is not restricted to any industry. The owners or the senior marketing managers who are believed to have enough knowledge about the marketing activities and strategies to answer the questionnaire and are the decision makers in the firm are chosen as the respondents. The answers were obtained with face to face interviews. 400 Firms were chosen but some of them either could not be reached or rejected to answer the questionnaire. After reviewing the answered questionnaires, 169 of them were decided to be used in the analysis. The response rate is $42 \%$, which is satisfactory to carry out the analysis. To test non-response bias, independent t-test to compare early and late respondents was carried out and no significant difference was found.

\subsection{Measures}

The measurements had been standardized and validated by other researchers. Measures were pilot tested using marketing managers. The questionnaire was also reviewed by some other academicians. All measures were tested with three item scales. The reliabilities of the scales are assessed by using Cronbach's Alpha and Table 1 shows the reliabilities of the scales, which are all above 0.70 that is recommended and the used value in most researches. 5-Point Likert-like scales are used to measure the variables $(1=$ strongly disagree, $5=$ strongly agree $)$.

The marketing managers are asked to compare the current performance of their firms in 2007 with performance standards mentioned earlier. The dimensions of performance standards asked to the marketing managers to compare are return on investment, increases in sales, and overall performance evaluation. These dimensions are used in the scales developed by Dess and Robinson (1984), Pelham and Lieh (2004), Brouthers and Xu (2002), Matsuno et al. (2000), and Miller (1987). The marketing managers are asked about the innovations they did in 2008 with their products and production process with 5 items used by Denison (1990). The reliability of comparison of the performance (performance in 2007) with past performance (performance in 2006) is 0.72 . The reliability of comparison of the performance with the target performance for 2007 is 0.77 . The reliability of comparison of the performance with competitor performance is 0.82 and the reliability of comparison of the performance with average industry performance is 0.72 . The reliability of items about innovation is 0.91 . The items were computed and the dependent and independent variables were formed to be used in the analyses.

\subsection{Correlations}

Descriptive statistics related to the constructs in the model are shown in Table 2. In the research, links between innovation and comparison of the performance with past performance, target performance, competitor performance, and industry performance are investigated. No correlation is found with innovation and comparison of performance with past performance. This might be due to the factor that in highly turbulent environment, managers mainly focus on the future rather than the past. There is low negative correlation between innovation and comparison of the current performance with target performance $(r=-0.16, p<0.05)$. Innovation doesn't correlate with comparison of performance with competitors. There is a negative weak correlation between innovation and comparison of the current performance with the average performance of the industry $(\mathrm{r}=-0.21, \mathrm{p}<0.01)$.

\subsection{Regression Analysis}

Regression analysis is used to test the research model. The results are summarized in Table 3 . The overall fit of the model was good and the model is significant at 0.01 level and adjusted $\mathrm{R}$ square is 0.05 . The independent variables, which are comparison of performance with past performance of the firm, target performance of the related term, performance of the main competitor/s, average performance of the industry, explain 5\% of the variance in the dependent variable innovation. The explained variance is low as expected to the reason that there so many other factors that have impact on dependent variable innovation. The correlations are high among the independent variables, indicating the multicollinearity problem. To get rid of the effects of multicollinearity caused by the linear relationship among the explanatory variables, variance inflation factor is applied.

$\mathrm{H} 1$ (if the firms perform better than the past performance, they don't make innovation: beta value $=0.21, \mathrm{sig}=0.03$ ) is rejected. This means if the firm performs better than the past, marketing managers decide to make innovation. The 
reason for that might be managers are motivated to make innovation when they see positive results of making innovation. Moreover, having better results might be presenting some financial resources to the firm to make innovation. H2 (If the firms perform better than the target performance of the firm, they don't make innovation: beta value $=-0.20, \mathrm{sig}=0.04$ ) is accepted. If firms reach a better performance level than their target performance, marketing managers are content with the results and don't feel to make any further changes. As mentioned in the literature review, making a change is risky, and that is why they may prevent from taking risks. H3 (If the firms perform better than the competitors' performance, they don't make innovation: beta value $=0.04$, sig $=0.63$ ) is not accepted. The possible reason for this might be that managers of small and medium sized firms either fail to identify their competitors or cannot get information about their competitors. That is why this performance evaluation type has no effect on the dependent variable. H4 (If the firms perform better than the average performance of the industry, they don't make innovation: beta value $=-0.22$, sig $=0.04$ ) is accepted. If firms are doing better than the average industry, they are content with their position in the market and don't need to make innovation. The possible reason for not making innovation might be the intention of the managers to avert risk which could occur as a result of innovation.

\section{Conclusion}

In a highly competitive environment, one of the main functions of marketing managers is to follow the environment and firm fit. The prevailing change in the environment forces the firms to adapt to the changing environment, and this is possible by making innovation at the right time, at the right frequency, at the right aspects of the firm, and in the right way. In this research paper, only when is the right time to make innovation is searched. The first step is to measure the firms' performances. Performance measurement is vital for companies, as is the evaluation of it, so the next step involves comparing its performance with predetermined performance standards. In effect, comparison is a widely used technique to evaluate performance, which enables to remark the extent of being better than, similar to, equivalent to, or worse than these standards. Main performance comparison standards are past performance of the firm, target performance of the firm, performance of the competitor, and/or average performance of the industry. Using just one of them is believed to be inadequate to discern the position of the firm in the market environment. By using all these standards at the same time, marketing managers would not only focus on their performance but also on competitors' and industry's average performance. On the other hand, just using one of them might be misleading for managers.

In the model proposed in this research, it is found out that even if firms perform better than the past, they make innovation. This might be explained with some factors related to the industry. While performing better than past, if the performance of the firm falls behind the average performance of the industry, managers may feel obliged to make innovation. Though it is out of the scope of this study, customers might also force the firms to make innovation. Performing better than the target performance of the firm denotes the success of the firm, so companies might be reluctant to make innovation. It is unexpected to find out that firms do not take the performance of the competitor into consideration upon evaluating their performance. However, managers should find a way to obtain information about the competitors not to lose competitive advantage.

This study consists of several limitations. One of them is that the sample is too small to generalize the results. Another one is this research is carried out during a very heavy global economic crisis in the world, so the results might have been influenced from it. Moreover, there are so many antecedents of making innovation, so it would be simplistic to explain innovation with managers' performance evaluation. The size of the company, availability slack resources, and the ability to make innovation are some of the antecedents.

In this research, the sample was drawn from different industries to make generalization, so in the future some researches should be carried out in various industries to observe the differences among the industries. Furthermore, researchers should investigate the effects of the kind of comparison standards marketing managers use on their decisions about different activities they carry out in the firms. In the literature, different types of performance standards are used in various studies, but none of them has looked into which one is more effective on managers' decision making process. The model in this model should be tested with other researches. Moreover, the sample in this research was chosen from small and medium sized firms, so studies might be done with big companies. 


\section{References}

Arndt, M. and Bigelow, B. (2000). 'Presenting structural innovation in an institutional environment: Hospitals' use of impression management', Administrative Science Quarterly, Vol. 45, No. 3, pp. 494-522. http://dx.doi.org/10.2307/2667107

Bourgeois, L. J. III. (1980). 'Performance and consensus', Strategic Marketing Journal, Vol. 1, No. 3, pp. $227-248$.

Brooks, W. K. and Coleman, G. D. (2003). 'Evaluating key performance indicators used to drive contractor behaviour at AEDCQ engineering', Management Journal, Vol. 15, No. 4, 24-39.

Brouthers, L. E. and Xu, K. (2002). 'Product stereotypes, strategy and performance satisfaction: The case of Chinese exporters', Journal of International Business Studies, Vol. 33, No. 4, pp. 657-678. http://dx.doi.org/10.1057/palgrave.jibs.8491038

Chakravarty, B. S. (1986). 'Measuring strategic performance', Strategic Management Journal, Vol. 7, No. 5, pp. 437-458.

Cooper, L. G. (2000). 'Strategic marketing planning for radically new products', Journal of Marketing, Vol. 64, No. 1, pp. 1-16. http://dx.doi.org/10.1509/jmkg.64.1.1.17987

Coşkun, A. (2006). 'STK'ların stratejik performans yönetiminde yeni bir yaklaşım: Performans karnesi' Sivil Toplum, Vol. 4, No. 15, pp. 103-117.

Denison, D. R. (1990). Corporate Culture and Organizational Effectiveness. New York: Wiley.

Dess, G. G. and Robinson, R. B. (1984). 'Measuring organizational performance in the absence of objective measures: The case of the privately-held firm and conglomerate business unit', Strategic Management Journal, Vol. 5, No. 3, pp. 265-273. http://dx.doi.org/10.1002/smj.4250050306

Epstein, M. J. and Roy, M. (2005). 'Evaluating and monitoring CEO performance: Evidence from US compensation committee reports', Corporate Governance, Vol. 5, No. 4, pp. $75-88$. http://dx.doi.org/10.1108/14720700510616604

Geringer, J. M. and Hebert, L. (1991). 'Measuring performance on their international joint ventures', Journal of International Business Studies, Vol. 22, No. 2, pp. 249-264. http://dx.doi.org/10.1057/palgrave.jibs.8490302

Greve, H. R. (1998). 'Performance, aspirations, and risky organizational change', Administrative Science Quarterly, Vol. 43, pp. 58-86. http://dx.doi.org/10.2307/2393591

Greve, H. R. and Taylor, A. (2000). 'Innovations as catalysts for organizational change: Shifts in organizational cognition and search', Administrative Science Quarterly, Vol. 45, No. 1, pp. $54-80$. http://dx.doi.org/10.2307/2666979

Han, J. K., Namwoon, K., and Rajendra, K. S. (1998). 'Market orientation and organizational performance: Is innovation a missing link?', Journal of Marketing, Vol. 62, No. 4, pp. 30-45. http://dx.doi.org/10.2307/1252285

Hansen, G. S. and Wernerfelt, B. (1989). 'Determinants of firm performance: The relative importance of economic and organizational factors', Strategic Management Journal, Vol. 10, No. 5, $399-411$. http://dx.doi.org/10.1002/smj.4250100502

Hurley, R. F., Tomas, G., and Hult, M. (1998). 'Innovation, market orientation, and organizational learning: An integration and empirical examination', Journal of Marketing, Vol. 62, No. 3, pp. $42-54$. http://dx.doi.org/10.2307/1251742

Johnston, W. J. and Kim, K. (1994). 'Performance, attribution, and expectancy linkages in personal selling', Journal of Marketing, Vol. 58, No. 4, pp. 68-81. http://dx.doi.org/10.2307/1251917

Kennerley, M. and Neely, A. (2003). 'Measuring performance in a changing business environment', International Journal of Operations and Production Management, Vol. 23, No. 2, pp. 213-229. http://dx.doi.org/10.1108/01443570310458465

Kernan, M. C. and Lord, R. G. (1991). 'An application of control theory to understanding the relationship between performance and satisfaction', Human Performance, Vol. 4, No. 3, pp. 173-185. http://dx.doi.org/10.1207/s15327043hup0403_1

Lindsley, D., Brass, D. J., and Thomas, J. B. (1995). 'Efficacy- performance spirals: A multi-level perspective', The Academy of Management Review, Vol. 20, No. 3, pp. 645-678. 
Matsuno, K. and John, T. M. (2000). 'The effects of strategy type on the market orientation-performance relationship', Journal of Marketing, Vol. 64, No. 4, pp. 1-16. http://dx.doi.org/10.1509/jmkg.64.4.1.18078

Miller, D. (1987). 'Strategy making and structure: Analysis and implications for performance', Academy of Management Journal, Vol. 30, No. 1, pp. 7-32. http://dx.doi.org/10.2307/255893

Pelham, A. M. and Lieh, P. (2004). 'Differences between presidents' and sales managers' perceptions of the industry environment and firm strategy in small industrial firms: Relationship to performance satisfaction', Journal of Small Business Management, Vol. 42, No. 2, pp. 174-189. http://dx.doi.org/10.1111/j.1540-627X.2004.00104.x

Piercy, N. F., Kaleka, A., and Katsikes, C. S. (1998). 'Sources of competitive advantage in high performing exporting companies', Journal of World Business, Vol. 33, No. 4, pp. 378-393.

Sivadas, E. and Dwyer, F.R. (2000). 'An examination of organizational factors influencing new product success in internal and alliance-based processes', Journal of Marketing, Vol. 64, No. 1, pp. 31-49. http://dx.doi.org/10.1509/jmkg.64.1.31.17985

Smith, A. K. and Bolton, R. N. (2002). 'The effect of customers' emotional responses to service failures on their recovery effort evaluations and satisfaction judgments', Academy of Marketing Science, Vol. 30, No. 1, pp. 5-23. http://dx.doi.org/10.1177/03079450094298

Tekin, H. (1993). Eğitimde Ölçme ve Değerlendirme. İstanbul: Yargı Yayınevi.

Wirtz, J. and Mattila, A. (2001). 'Exploring the role of alternative perceived performance measures and needs-congruency in the consumer satisfaction process,' Journal of Consumer Psychology, Vol. 11, No. 3, pp. 181-192. http://dx.doi.org/10.1207/S15327663JCP1103_04

Zou, S. and Cavusgil, T. (2002). 'The GMS: A broad conceptualization of global marketing strategy and its effect on firm performance', Vol. 66, No. 4, pp. 40-57.

Table 1. Reliability of the measures

\begin{tabular}{|c|c|}
\hline Measures & Cronbach's Alpha \\
\hline comparison of performance with past performance & 0,72 \\
\hline comparison of performance with target performance & 0,77 \\
\hline comparison of performance with competitor performance & 0,82 \\
\hline comparison of performance with average industry performance & 0,72 \\
\hline innovation & 0,91 \\
\hline
\end{tabular}

Table 2. Descriptive Statistics and correlations

\begin{tabular}{|l|c|c|c|c|c|c|c|}
\hline & Means & Std. Dev. & 1 & 2 & 3 & 4 & 5 \\
\hline 1. Com. past per. & 3,70 & 0,89 & 1 & & & & \\
\hline 2. Com. target per. & 3,26 & 0,95 &, $62 * *$ & 1 & & & \\
\hline 3. Com. competitor per. & 3,52 & 0,93 &, $24 * *$ &, $42 * *$ & 1 & & \\
\hline 4. Com. average ind. per. & 3,32 & 0,90 &, $37 * *$ &, $49 * *$ &, $68^{* *}$ & 1 & \\
\hline 5. Innovation & 3,31 & 1,24 &, 01 &,$- 16^{*}$ &,- 14 &,$- 21^{* *}$ & 1 \\
\hline
\end{tabular}

$$
* * \mathrm{p}<0.01 \quad * \mathrm{p}<0.05
$$


Table 3. Regression results

\begin{tabular}{|l|c|c|c|}
\hline Independent variables & St. Beta Coeffi. & t-Value & Sig. Level \\
\hline Constant & & 8,11 & 0,00 \\
\hline Com. past per. & 0,21 & 2,16 & 0,03 \\
\hline Com. target per. & $-0,20$ & $-1,98$ & 0,04 \\
\hline Com. competitor per. & 0,04 & 0,47 & 0,63 \\
\hline Com. industry per. & $-0,22$ & $-2,05$ & 0,04 \\
\hline
\end{tabular}

Dependent Variable: Innovation

Adjusted R Square $=5 \%$, significant at 0.01 level

$\mathrm{F}$ value $=3,457$

$$
\mathrm{df}=4 \quad \text { residual }=164
$$

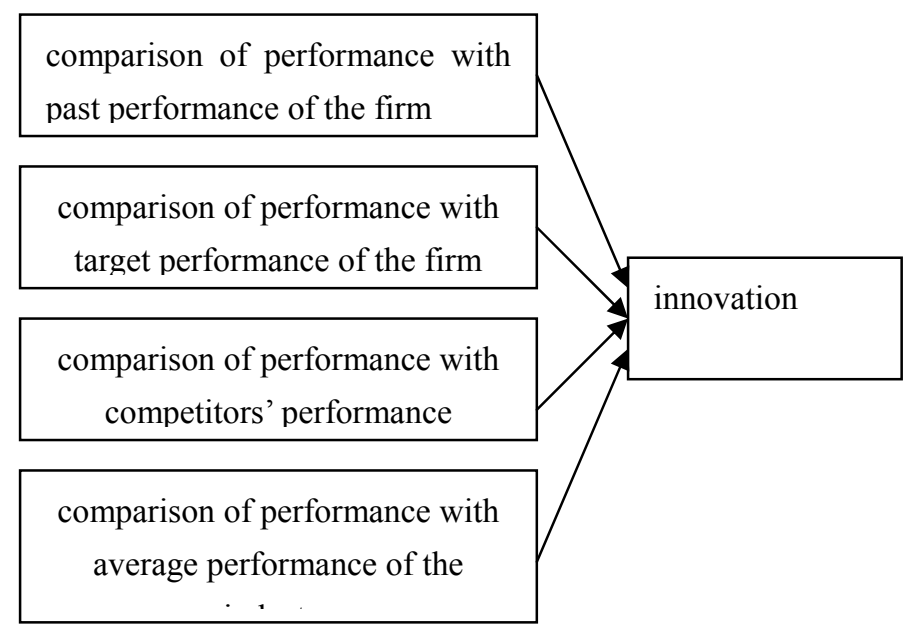

Figure 1. Model 